\title{
Carbon Footprint Analysis for the Waste Oil Management System in Portugal
}

\author{
Ana Pires ${ }^{1,2^{\star}}$ and Graça Martinho ${ }^{2}$ \\ ${ }^{1}$ UNINOVA-Ca ${ }^{3}$, Caparica, Portugal. \\ ${ }^{2}$ Departamento de Ciências e Engenharia do Ambiente, Faculdade de Ciências e \\ Tecnologia, Universidade Nova de Lisboa, 2829-516 Caparica, Portugal.
}

Authors' contributions

This work was carried out in collaboration between all authors. AP designed the study, managed the literature searches, performed the carbon footprint analysisand wrote the first draft of the manuscript. GM managed the analyses of the study. All authors read and approved the final manuscript.

Research Article

Received $2^{\text {nd }}$ October 2012 Accepted $10^{\text {th }}$ October 2012 Published 15 ${ }^{\text {th }}$ October 2012

\section{ABSTRACT}

Aims: The study analyzes the carbon footprint of the waste oil management system operating in Portugal to ensure the sustainable operation in the future. The analysis was carried out in 2011 for the system that is composed of a treatment procedure collecting the treated oil for re-refining, followed by the production of expanded clay and recycling for electricity production.

Methodology: Carbon footprint analysis was conducted by using the Umberto software 5.5 based on the concepts of life cycle assessment with respect to international standards (ISO). Within this context, the substances considered for such carbon footprint analysis are directly relevant to Intergovernmental Panel on Climate Change (IPCC, 2007).

Results: The results showed that managing waste oils may contribute to the reduction of carbon footprint due to the avoided emissions of greenhouse gas through the reuse of treated waste oils. The carbon dioxide equivalent emissions from collection and treatment of waste oils would not outweigh such benefit earned from the substitution of virgin lubricant oil even though the use of treated waste oils for producing expanded clay may end up some more carbon dioxide emissions.

Conclusion: The carbon footprint analysis in this study has shown the potential for improvements in the waste oil management system in Portugal. The most significant 
improvement that could be made is the increase of using treated waste oils for the expanded clay production. However, such a strategy would not be consistent with the waste hierarchy principle which dominates the current decision making in managing waste nationally.

Keywords: Waste oils; re-refining; expanded clay; electric energy; carbon footprint; waste hierarchy principle.

\section{INTRODUCTION}

In 2008, around 5.6 million of metric tonnes of waste lubricating oils (WOs) were generated in European Union (EU) (Eurostat, 2008). These WOs are hazardous and may result in ecotoxic, harmful and carcinogenic effects (EA, 2007) as verified by the European Waste Catalogue (code 13). For these reasons, these WOs have been classified as hazardous waste that requires proper handling through the correct and safer ways. The mismanagement, however, will end up a risk of water pollution if being dumped in sewers and rivers or tipped on soil. WOs, or scrap oils, or waste oils can contaminate freshwater, with unintended impacts on aquatic plants and fish, water treatment facilities, and even human health (Fitzsimons, 2006). Nevertheless, WOs are also considered as a kind of resources since they can be reused as a fuel or re-refined to be new base oils resulting inpotential saving of primary non-renewable resources (Fitzsimons, 2006).

The importance of managing this particular hazardous waste was reflected by the publication of the first directive for waste management through the Directive 75/439/EEC (EEC, 1975) and its amendments. The concern at that time was to ensure that these WOs can be properly collected and disposed of by appropriate processing, destruction, storage or tipping above or underground, in which the regeneration (also named re-refining) is deemed as the priority recovery option. The discharge of these WOs or the residues resulting from their processing into water bodies and soil are banned; mixing of these WOs with polychlorinated biphenyls and polychlorinated terphenyls (PCBs and PCTs) or with toxic dangerous wastes is unauthorized (Pires and Martinho, 2012a).

Member States of EU have been capable of implementing measures to fulfill the WOs Directive requirements. For example, the preference of using re-refining techniques to treat WOs has been mainly implemented at in place in several countries like Greece, Luxembourg, Belgium, Denmark, Germany, Italy, Netherland and Poland, all of which have reached high re-refining rates (over $70 \%$ ). Other countries in EU have also promoted the combustion of these WOs (Ecologic and IEEP, 2009). Many countries in EU have adopted to establish free market basis management, and have promoted extended producer responsibility (EPR) program to reinforce management strategies.

Portugal is one of those countries that have implemented EPR to manage these WOs. The EPR system is known as SIGOU (WOs management system, in Portuguese Sistemalntegrado de Gestão de ÓleosUsados) and is managed by SOGILUB (WOs management organization, in Portuguese Sociedade de Gestãolntegrada de ÓleosLubrificantesUsados) producer responsibility organization. The SIGOU is only devoted to managing the oils that generate these WOs, with predefined specifications concerning PCBs (lower than 50 ppm), water and sediment contents. The SIGOU includes the collection 
and treatment. Collection is performed by waste transportation companies following predetermined routes. The collected WOs are then delivered to mild processing units, with different technologies. After treatment, the WOs are sent to three main destinations: light expanded clay aggregate production, re-refining and recycling followed by power generation. SOGILUB needs to comply with the national management targets, which are the collection of at least $85 \%$, recycling of at least $50 \%$ based on collected WOs, and re-refining of at least $25 \%$ based on collected WOs. In reality, in 2011 , all collected WOs were treated, being $51 \%$ sent to recycling units and power plants, $40 \%$ for re-refining and the rest $(9 \%)$ of them for expanded clay production (A. Vicente, SOGILUB, personal communication). To financially sustain the system, a fee $(0.063 € /$ liter $)$ is charged to consumers at the moment of buying lubricant oil, and also through the treated WOs auctions. Who gets compensated by their work are collectors and treatment units.

Ensuring that SOGILUB manages WOs with the best sustainable way possible is actually tied to the assessment of SIGOU's carbon footprint when greenhouse gas (GHG) emissions are of big concern. "Carbon footprint" is a term that is commonly used to describe the amount of GHG emissions caused by a particular activity or entity (Boguski, 2010). Carbon footprint has been applied to several waste management systems very recently. For instance, Browne et al. (2009) calculated a carbon footprint indicator to measure the environmental impacts of production, domestic disposal, recycling and exports of waste produced by the residents of an Irish city and to analyze the likely impact of policy scenarios relating to waste reduction, increased recycling, thermal treatment and disposal by landfill. Mühle et al. (2010) compared municipal solid waste management systems in both United Kingdom and Germany based on carbon footprint. Jeswani et al. (2012) concluded that incineration offers significant savings of GHG compared to disposal of waste at landfills. This study therefore analyzes the carbon footprint of SIGOU system and allows us to further identify which improvements can be made possible to improve the systematic performance. The carbon footprint applied in this study is based on global warming environmental impact determination through life cycle assessment methodology (LCA). Several authors have analyzed global warming of waste management systems like Blengini (2008), Blengini et al. (2012), Cleary (2010), Gentil et al. (2010), Grosso et al. (2012), McDougall et al. (2001), Pires and Martinho (2012b), Pires et al. (2011), Rigamonti et al. (2010), Scipioni et al. (2009), Williams et al. (2010), which has been useful for the analysis of the LCA methodology applied to this purpose.

\section{METHODOLOGY}

The carbon footprint is estimated by calculating the embodied energy and GHG emissions associated with lubricant oil consumption, i.e., the amount of energy consumed during the full life cycle of material extraction, production, delivery and disposal of a specific good or service (Brown and Herendeen, 1996). Until now there is no international standard for the analysis of carbon footprints. International Standards Organization (ISO) is developing ISO 14067 for carbon footprint analysis and lubricant oil communication, including labeling, which is expected to be published in 2013. In the present study, the ISO Standards for LCA (ISO, 2006) were applied to conduct the carbon footprint analysis. Besides, the Intergovernmental Panel on Climate Change (IPCC, 2006) was referred to as a relevant guideline for assessing the GHG sources and sinks in the context of carbon footprint analysis.

In accordance with the IPCC (2006), the carbon dioxide $\left(\mathrm{CO}_{2}\right)$ emissions arising from biogenic carbon sources are excluded from the calculation of GHG emissions from the life cycle of products, except where carbon dioxide arises from land use change. In addition to 
carbon dioxide, other GHG substances such as methane, nitrous oxide, chlorofluorocarbons, hydrocarbons, perfluorinated compounds, fluorinated ethers, and perfluoropolyethers are considered in this carbon footprint analysis. Note that the substances of perfluoropolyethers are listed in PAS 2050 (BIS, 2011), with global warming potential in accordance with IPCC (2007). With all data available, the carbon footprint analysis was conducted with Umberto software version 5.5 .

\subsection{Scope and Boundaries}

Ideally, the LCA should begin at raw material extraction, in this case petroleum extraction, virgin base oil production, use of lubricant oil and finally end-of-life treatment, i.e. the cradle to grave approach. However, a zero burden assumption may be applied for studying waste systems, simplifying the assessment and narrowing the LCA to the waste treatment and recovery fields. This assumption considers that the waste carries no upstream environmental burden into the waste management system (Ekvall et al., 2007); in other words, all life cycle stages prior to the waste phase can be omitted if they are common to all subsequent waste management options (Finnveden, 1999; Buttol et al., 2007). This is the situation occurring in the WOs system. Zero burden approach is applied by several to waste management LCA studies which can be found in literature (Blengini, 2008; Cleary, 2010; Gentil et al., 2010; Grosso et al., 2012; McDougall et al. 2001; Pires and Martinho, 2012b; Pires et al., 2011; Rigamonti et al., 2010; Scipioni et al., 2009; Williams et al., 2010).

The main purpose of this study is to know the carbon footprint resulting from the management of these WOs only in Portugal. The present WOs management system is delineated in Fig. 1. The functional unit of this study is the amount treated in 2011 in Portugal, 26,946 tonnes (A. Vicente, SOGILUB, personal communication). The relevance of using such amount is related to the need to quantify correctly the amount of GHG emitted during the WOs collection.

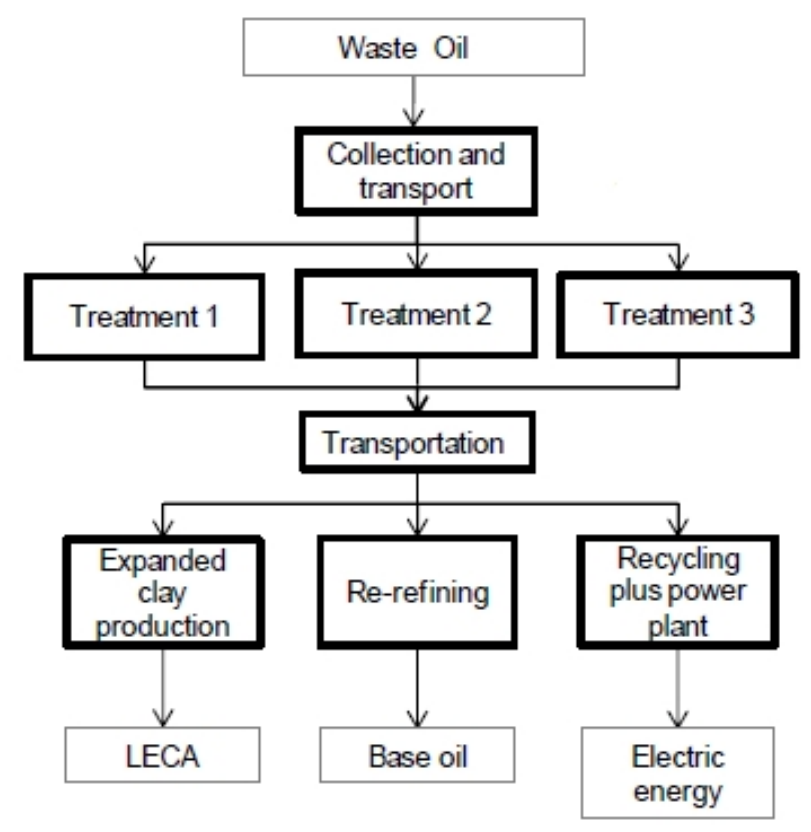

Fig. 1. SIGOU system in 2010 
In the case of upstream GHG, inventory concerning fuel extraction, mining, fuel transport were considered, being the respective inventory present in auxiliary materials chapter. Also downstream GHG related to waste and wastewater managements are also considered in the study. The GHG emissions from substituted materials were also considered in the study.

\subsection{Inventory Analysis}

The information used to conduct GHG inventory was based on data from SOGILUB, Umberto library and European Monitoring and Evaluation Program (EMEP/Corinair) data, for air emissions. Some more information from the issuance of environmental licenses and related environmental impact assessment studies was considered too.

\subsubsection{WOs collection and transport}

WOs collection and transport are provided by several waste transportation companies, and in some instances is the same company that owns the treatment plant. WOs from the Madeira and Azores Autonomous Regions are treated in continental Portugal, being transported by cargo ship. The distances travelled in 2010 from the Madeira and Azores Autonomous Regions to Portugal are assumed to be $860 \mathrm{~km}$ and $1,280 \mathrm{~km}$, respectively. In continental Portugal, collection is made along routes predetermined in accordance with the waste producers' capacity to retain WOs and the distance to the depository areas. According to SOGILUB (2010), the total collection distance travelled in continental Portugal was $161,273 \mathrm{~km}$. The transportation was made using a lorry with a 24-tonne capacity, being assumed $16 \mathrm{~L} / 100 \mathrm{~km}$ diesel consumption.

\subsubsection{WOs treatment}

The existing treatments used by SIGOU are mild reprocessing treatments, which remove water and sediments from WOs. The treatments usually involve the setting of solids and water, centrifugation, and membrane filtration. The input material is WOs, the waste resulting from the treatment of mostly oiled sludge and wastewater.

Regardless of the simplicity of the treatment, each unit presents different treatment schemes, which makes each process slightly different. Mild processing unit 1 uses electric energy (11.8 MWh/t WOs) and diesel (14.2 kg/t WOs) (Recurso, 2003; APA, 2004). Mild processing 2 use electric energy (14.9 MWh/t WOs) and liquid gas (5.8 kg/t WOs) (APA, 2006; Techninvest, 2005). Treatment 3 uses electric energy (15.1 MWh/t WOs) and fuel oil light (4.7 kg/treated WOs) (APA, 2008; EIPPCB, 2006).

After the WOs have been treated, it is transported to recovery units by lorries with a 24tonne capacity, and a consumption of $26 \mathrm{~L} / 100 \mathrm{~km}$. The distance travelled is around $450 \mathrm{~km}$, depending on the facilities' locations (one of the re-refining facilities is located in Spain, around 11,740 tonnes of WOs for re-refining) and the quantity of treated WOs to be transported. Treated WOs are also sent to Germany for re-refining (996 tonnes), being the transportation made by ship, with a distance of $2,500 \mathrm{~km}$, in average.

\subsubsection{WOs recovery}

The recovery options are re-refining, expanded clay production and recycling for energy production, all of which involve the release of GHG. With regard to the expanded clay 
production, all treated WOsare applied to the clay. Concerning the re-refining option, the plant considered applies a propane deasphalting process, producing base oil, flux oil, light ends, asphaltic residue, and light fuel oil. Flux oil, light ends, and asphaltic residue are all applied as an additive to bitumen, and light fuel oil is burned in the unit to produce steam and heat. Recycling and electric energy production are made through thermal cracking, where heat is used to break down long-chain hydrocarbon molecules (e.g., those found in WOs) into shorter ones, thus generating lighter liquid fuels (EIPPCB, 2006). According to Pires and Martinho (2012b), the outputs of the existing thermal cracking unit in Portugal include marine fuel oil, heavy residues, and oiled water. The marine fuel oil is then used in the facility to produce electric energy, released as gaseous pollutants. The oiled water and heavy residues are sent to hazardous waste landfills.

\subsubsection{Auxiliary materials and substituted materials}

The most relevant auxiliary materials are the fuels used during the treatment process and electric energy (i.e. the diesel required for collection and transportation has already been mentioned). The production inventory and the use of those materials are based on Umberto library and EMEP/Corinair (2007), EMEP/EEA (2009).Concerning auxiliary materials, Portuguese electric energy is generated using the following sources (ProBas, 2010; GEMIS, $2001)$ : coal $(28.10 \%)$, fuel oil $(8.37 \%)$, natural gas $(30.50 \%)$, biomass $(0.55 \%)$, hydro $(25.00 \%)$, waste $(7.00 \%)$, geothermic $(0.33 \%)$, and wind $(0.15 \%)$.

Concerning substituted materials, re-refined base oil from re-refining can substitute virgin base oil in 1:1 substitution ratio; expanded clay, where WOs is used as expansion agent can substitute in 1:1 basis the virgin base oil; and electric energy from WOs recycling plus power plant can substitute electric energy mix consumed in Portugal in a 1:1 basis.

The inventory, conducted to produce and use substituted materials and energy, was developed using several data sources. With regard to virgin base oil production, it has been claimed that virgin base oil in Portugal contains on average 10\% synthetic base oils (Pawlak, 2003; Whitby, 2004), and this is taken into account in the life cycle inventory. The inventory related to virgin base oil production is from Ifeu (2005). Electric energy mix inventory is obtained from ProBas (2010) and GEMIS (2001).

\section{RESULTS AND DISCUSSION}

The results presented in Fig. 2 expresses in tonne of $\mathrm{CO}_{2}$ equivalent per total amount of WOs treated, illustrate that the net $\mathrm{CO}_{2}$ emissions associated with the management of WOs is mostly associated with the avoided burden obtained from the re-refining process in the actual situation. Emissions of carbon footprint can be observed from WOs collection and transportation and treatment, which are lower than the avoided emissions from the different recovery options.

By comparing the actual situation with the hypothetical scenario where recovery options are maximized, the hypothetical scenario has about 1.8 times of the net GHG emissions lesser than the actual situation in terms of $\mathrm{CO}_{2}$ equivalent per total amount of WOs treated for expanded clay. The key factor that contributes to this difference is the amount of $\mathrm{CO}_{2}$ equivalent saved during expanded clay production $(311 \mathrm{kgCO} / \mathrm{kg}$ expanded clay) and reduced release of $\mathrm{CO}_{2}$ during WOs treatment, compared to the counterpart of production of expanded clay using virgin lubricant oil. 


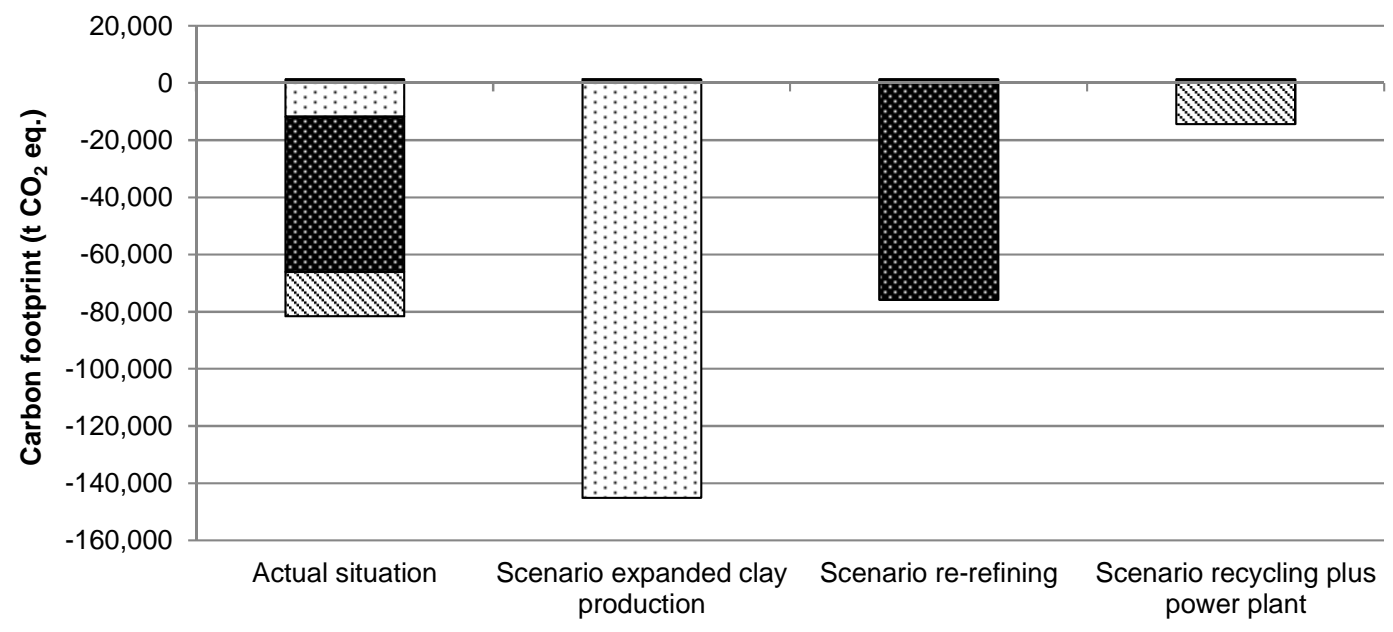

$₫$ Collection and transport mTreatment $\square$ Expanded clay production $\mathbf{m}$ Re-refining $\mathbf{Q}$ Recycling plus power plant

Fig. 2. Comparison of the carbon dioxide equivalent emissions from WOs management in Portugal: actual situation and scenarios

The worst scenario would be the use of treated WOs during recycling with energy recovery to produce electricity. This option is a less efficient one due to GHG emissions during the combustion because in Portugal it is getting less GHG emissions in electricity production due to the use of renewable sources of energy.

Possible managerial improvement of WOs can be justified by EU legislation and Portuguese legislation which intends to follow waste hierarchy principle and reduce environmental impacts. In fact, the results reached during the carbon footprint analysis show that sending treated WOs to a recovery unit followed by electricity production in a power plant, one of the latest options considered according to the waste hierarchy principle is not a viable option to be maintained due to its higher carbon footprint. However, re-refining option does not exhibit advantages in terms of carbon footprint, although it is favored based on the waste hierarchy principle. Besides, economic aspects such as the costs and revenues from managing WOs must also be addressed when studying possible improvements in WOs management. Looking into other environmental criteria such as resources depletion and human toxicity can lead to a more environmentally benign option needed to well manage these WOs.

\section{CONCLUSIONS}

This research found that the careful management of these WOs can be a useful way to contribute to the reduction of GHG release at the national level. Overall, the GHG emissions resulting from expanded clay production using treated WOs receives the highest credit in terms of carbon footprint. These findings would not support the favored options that are selected based on the waste hierarchy principle. This implies that the recovery of treated WOs for expanded clay production is significantly better than re-refining option which is the priority given by waste hierarchy principle. This is due to the fact that waste hierarchy principle is given in a perspective of material conservation rather than environmental impact including carbon footprint and climate change perspectives. It is therefore suggested that the 
WOs management must be adapted to comply with the waste hierarchy principle, however, with respect to the possible environmental impacts. Future studies should be directed to the carbon footprint analysis associated with separated collection of different types of WOs to assess individual environmental impact and further improve the risk management in the context of climate change. SOGILUB should focus more in re-refining and expanded clay production options and abandon recycling plus electric energy production.

\section{ACKNOWLEDGEMENT}

The authors are grateful for the support they received from SOGILUB.

\section{COMPETING INTERESTS}

Authors have declared that no competing interests exist.

\section{REFERENCES}

APA. (2004). Environmental licenses (in Portuguese). Agência Portuguesa do Ambiente. http://aiacirca.apambiente.pt:8980/Public/irc/aia/la/library. (accessed 10 March 2010).

APA. (2006). Environmental licenses (in Portuguese). Agência Portuguesa do Ambiente. http://aiacirca.apambiente.pt:8980/Public/irc/aia/la/library. (accessed 10 March 2010).

APA. (2008). Environmental licenses (in Portuguese). Agência Portuguesa do Ambiente. http://aiacirca.apambiente.pt:8980/Public/irc/aia/la/library. (accessed 10 March 2010).

Blengini, G.A. (2008). Using LCA to evaluate impacts and resources conservation potential of composting: A case study of the Asti District in Italy. Resources, Conservation and Recycling, 52, 1373-1381

Blengini, G.A., Fantoni, M., Busto, M., Genon, G., Zanetti, M.C. (2012). Participatory approach, acceptability and transparency of waste management LCAs: case studies of Torino and Cuneo. Waste Management, 32, 1712-21.

Boguski, T.K. (2010). Life cycle carbon footprint of the National Geographic magazine. The International Journal of Life Cycle Assessment, 15, 635-643.

Brown, M.T., Herendeen, R.A. (1996). Embodied energy analysis and EMERGY analysis: a comparative view. Ecological Economics, 19, 219-35.

Browne, D., O'Regan, B., Moles, R. (2009). Use of carbon footprinting to explore alternative household waste policy scenarios in an Irish city-region. Resources, Conservation and Recycling, 54, 113-122.

BSI. (2011). Publicly Available Specification PAS 2050:2011. Specification for the assessment of the life cycle greenhouse gas emissions of goods and services. British Standards Institution, London.

Buttol, P., Masoni, P., Bonoli, A., Goldoni, S., Belladonna, V., Cavazzuti, C. (2007). LCA of integrated MSW management systems: case study of the Bologna District. Waste Management, 27, 1059-1070.

Cleary, J. (2010). The incorporation of waste prevention activities into life cycle assessments of municipal solid waste management systems: methodological issues. International Journal of Life Cycle Assessment, 15, 579-589.

Ecologic, IEEP. (2009). A report on the implementation of Directive 1999/31/EC on the landfill of waste. European Commission. 
EA. (2007). How to find out if waste oil and wastes that contain oil are hazardous - A guide to the Hazardous Waste Regulations. Environment Agency. Available at: http://publications.environment-agency.gov.uk/PDF/GEHO0607BMTW-E-E.pdf. (accessed 15 April 2012).

EEC. (1975). Council Directive 75/439/EEC of 16 June 1975 on the disposal of waste oils. Official Journal, L 194, 23-25.

Ekvall, T., Assefa, G., Björklund, A., Eriksson, O., Finnveden, G. (2007). What life-cycle assessment does and does not do in assessments of waste management. Waste Management, 27, 989-996.

EMEP/EEA. (2009). EMEP/EEA air pollutant emission inventory guidebook - 2009. European Environment Agency. http://www.eea.europa.eu/publications/emep-eeaemission-inventory-guidebook-2009. (accessed 10 December 2010).

EMEP/Corinair. (2007). EMEP/CORINAIR Atmospheric Emission Inventory Guidebook. European Environment Agency. http://www.eea.europa.eu/publications/ EMEPCORINAIR5. (accessed 10 December 2010).

EIPPCB. (2006). Reference Document on the Best Available Techniques for the Waste Treatments Industries. European Integrated Pollution Prevention and Control Bureau. ftp://ftp.jrc.es/pub/ eippcb/doc/wt_bref_0806.pdf. (accessed 10 December 2010).

Eurostat. (2008). Hazardous waste. Eurostat. Available at: http://epp.eurostat.ec.europa.eu/ portal/page/portal/waste/data/wastestreams/hazardous_waste. (accessed 15 April 2012).

Finnveden, G. (1999). Methodological aspects of life cycle assessment of integrated solid waste management systems. Resources, Conservation and Recycling, 26, 173-87.

Fitzsimons, D. (2006). Improving markets for waste oils. In Improving Recycling Markets, OECD (Organization for Economic Co-Operation and Development), Paris, 51-80.

GEMIS. (2001). Global emissions models for integrated systems. Öko Institute. http://www.oeko.de/sergvice/gemis. (accessed 20 June 2010).

Gentil, E.C., Damgaard, A., Hauschild, M., Finnveden, G., Eriksson, O., Thorneloe, S., Kaplan, P.O., et al. (2010). Models for waste life cycle assessment: review of technical assumptions. Waste Management, 30, 2636-48.

Grosso, M., Nava, C., Testori, R., Rigamonti, L., Viganò, F. (2012). The implementation of anaerobic digestion of food waste in a highly populated urban area: an LCA evaluation. Waste Management \& Research,30, 78-87.

Ifeu. (2005). Ecological and energetic assessment of re-refining used oils to base oils. GEIR - Groupement Européen de l'Industrie de la Régénération. http://www.geir-news.com/. (accessed 10 December 2010).

IPCC. (2007). Climate Change 2007: Synthesis Report. Contribution of Working Groups I, II and III to the Fourth Assessment Report of the Intergovernmental Panel on Climate Change [Pachauri, R.K and Reisinger, A. (eds.)]. IPCC, Geneva, Switzerland.

IPCC. (2006). Guidelines for National Greenhouse Gas Inventories. Intergovernmental Panel on Climate Change. http://www.ipcc-nggip.iges.or.jp/public/2006gl/vol5.html. (accessed 10 July 2012).

ISO. (2006). Environmental management-life cycle assessment- requirements and guidelines. ISO 14044:2006. International Organization for Standardization, Geneva.

Jeswani, H.K., Smith, R.W., Azapagic, A. (2012). Energy from waste: carbon footprint of incineration and landfill biogas in the UK. The International Journal of Life Cycle Assessment. doi:10.1007/s11367-012-0441-8.

McDougall, F., White, P., Franke, M. (2001). Integrated Solid Waste Management: Life Cycle Inventory, second ed. Blackwell Science Ltd., Oxford, United Kingdom. 
Mühle, S., Balsam, I., Cheeseman, C.R. (2010). Comparison of carbon emissions associated with municipal solid waste management in Germany and the UK. Resources, Conservation and Recycling, 54, 793-801.

Pawlak, Z. (2003). Tribochemistry of lubricating oils. Tribology and Interface Engineering Series, n. 0 45. Elsevier, The Netherlands.

Pires, A., Martinho, G. (2012a). Waste lubricating oil management in Portugal: the experience of an extended producer responsibility approach. Proceedings of the 3rd International Conference on Industrial and Hazardous Waste Management Crete 2012. 12-14 September, Chania, Greece.

Pires, A., Martinho, G. (2012b). Life cycle assessment of a waste lubricant oil management system. International Journal of Life Cycle Assessment, doi: 10.1007/s11367-0120455-2.

Pires, A., Chang, N.-B., Martinho, G. (2011). Reliability-based life cycle assessment for future solid waste management alternatives in Portugal. International Journal of Life Cycle Assessment, 16, 316-337.

ProBas. (2010). El-KW-Park-PT-2010 (in German). ZumProBas-Projekt. Umweltbundesamt. http://www.probas.umweltbundesamt.de/. (accessed 15 January 2010).

Recurso. (2003). Environmental impact assessment of tranfer and modernization of industrial unit Correia\&Correia (in Portuguese). Correia\&Correia. Portugal.

Rigamonti, L., Grosso, M., Giugliano, M. (2010). Life cycle assessment of sub-units composing a MSW management system. Journal of Cleaner Production, 18, 16521662.

Scipioni, A., Mazzi, A., Niero, M., Boatto, T. (2009). LCA to choose among alternative design solutions: the case study of a new Italian incineration line. Waste Management, 29, 2462-74.

SOGILUB. (2010). Activity report (in Portuguese).SOGILUB. http://www.ecolub.pt/documentos/relatorio2010html. (accessed 10 March 2011).

Techninvest. (2005). CIRVER SISAV - Environmental impact assessment in Portuguese). Tecninvest. Portugal.

Whitby, R.D. (2004). Synthetic lubricants reach new heights. Tribology \& Lubrication Technology, September 1.http://www.allbusiness.com/energy-utilities/oil-gas-industryoil-processing/ 11454473-1.html. (accessed 26 March 2011).

Williams, T.G.J.L., Heidrich, O., Sallis, P.J. (2010). A case study of the open-loop recycling of mixed plastic waste for use in a sports-field drainage system. Resources, Conservation and Recycling, 55, 118-128.

(c) 2012 Pires \& Martinho; This is an Open Access article distributed under the terms of the Creative Commons Attribution License (http://creativecommons.org/licenses/by/3.0), which permits unrestricted use, distribution, and reproduction in any medium, provided the original work is properly cited. 